\title{
The least of 3 evils: Exposure to red blood cell transfusion, anemia, or both?
}

\author{
Gabriel Loor, MD, ${ }^{\mathrm{a}}$ Jeevanantham Rajeswaran, PhD, ${ }^{\mathrm{b}}$ Liang Li, PhD, ${ }^{\mathrm{b}}$ Joseph F. Sabik III, MD, ${ }^{\mathrm{a}}$ \\ Eugene H. Blackstone, MD, ${ }^{\mathrm{a}, \mathrm{b}}$ Keith R. McCrae, MD, ${ }^{\mathrm{c}}$ and Colleen G. Koch, MD, MS, MBA ${ }^{\mathrm{d}, \mathrm{e}}$
}

\begin{abstract}
Background: Anemia and red blood cell (RBC) transfusions are both associated with morbidity and mortality after cardiac surgery. Patients with the lowest hematocrit (HCT) values during cardiopulmonary bypass (CPB) are the most likely to receive a transfusion, which results in a double-negative exposure. We aimed to clarify the effects of anemia, transfusion, and their combination to identify which imposes the greatest risk of end-organ dysfunction and mortality.
\end{abstract}

Methods: From November 1, 2004, to November 1, 2009, 7942 patients underwent procedures requiring CPB and did not receive intraoperative or postoperative RBC transfusion, and 1202 received intraoperative RBC transfusion alone. They were divided into 4 groups: intraoperative nadir HCT $\geq 25 \%$ without RBC transfusion, $\geq 25 \%$ with RBC transfusion, $<25 \%$ without RBC transfusion, and $<25 \%$ with RBC transfusion. The relationship among HCT, RBC, and outcomes was studied using generalized propensity-score analysis. Outcomes included estimated glomerular filtration rate (eGFR), troponin, ventilatory support time, length of stay, and mortality.

Results: After risk adjustment, comparison of all 4 groups showed that double exposure to anemia $(\mathrm{HCT}<25 \%)$ and RBC transfusion was associated with the highest risk: lowest eGFR $(P=.008)$, highest troponin values $(P=.01)$, longest ventilator requirement $(P<.001)$, longest length of stay $(P<.001)$, and highest mortality $(P=.007)$. Single exposure to either HCT $<25 \%$ or RBC transfusion alone was associated with the next risk category, and the lowest morbidity risk was associated with neither exposure.

Conclusions: Although single exposure to anemia or RBC transfusion alone was associated with risk, it was generally lower than that of anemia and RBC exposure in combination. (J Thorac Cardiovasc Surg 2013;146:1480-7)

Supplemental material is available online.

Cardiac surgical patients face several potentially negative exposures in the perioperative period that pose risk for increased morbidity and mortality. Among these are the

From the Departments of Thoracic and Cardiovascular Surgery ${ }^{\mathrm{a}}$ and Cardiothoracic Anesthesia, ${ }^{\mathrm{d}}$ Heart and Vascular Institute; the Department of Quantitative Health Sciences, ${ }^{\mathrm{b}}$ Research Institute; Hematologic Oncology and Blood Disorders, ${ }^{c}$ Taussing Cancer Center, and Quality and Patient Safety Institute, ${ }^{\mathrm{e}}$ Cleveland Clinic, Cleveland, Ohio.

This study was funded, in part, by the Cleveland Clinic Department of Thoracic and Cardiovascular Surgery; the Sheikh Hamdan bin Rashid Al Maktoum Distinguished Chair in Thoracic and Cardiovascular Surgery, held by Dr Sabik; and the Kenneth Gee and Paula Shaw, PhD, Chair in Heart Research, held by Dr Blackstone. The study sponsors had no role in the design and conduct of the study; the collection, analysis, and interpretation of the data; or the preparation, review, or approval of the study.

Disclosures: Authors have nothing to disclose with regard to commercial support.

Received for publication Feb 14, 2013; revisions received June 10, 2013; accepted for publication June 27, 2013; available ahead of print Sept 3, 2013

Address for reprints: Colleen G. Koch, MD, MS, MBA, Department of Cardiothoracic Anesthesia, Cleveland Clinic, 9500 Euclid Ave/Desk J4-331, Cleveland, OH 44195 (E-mail: kochc@ccf.org).

$0022-5223 / \$ 36.00$

Copyright (c) 2013 by The American Association for Thoracic Surgery

http://dx.doi.org/10.1016/j.jtcvs.2013.06.033 threats of developing anemia and receiving red blood cell (RBC) transfusions. Our prior work and other investigations have recognized increased morbidity among cardiac surgical patients who develop perioperative anemia ${ }^{1-3}$ and receive RBC transfusions. ${ }^{1,4-7}$ Although both of these negative exposures may be avoidable, when physicians must decide whether to circumvent patient exposure to anemia by preemptive treatment with RBC transfusion or to simply tolerate anemia, the trade-off with morbidity risk is unclear.

Our objectives were to evaluate morbidity and survival associated with 3 operative management strategies in patients undergoing cardiac surgery requiring use of cardiopulmonary bypass (CPB): (1) tolerating anemia without RBC transfusion, (2) avoiding anemia with RBC transfusion, and (3) exposing patients to both anemia and its treatment, RBC transfusion.

\section{METHODS \\ Study Population}

From November 1, 2004, to November 1, 2009, 15,282 patients at Cleveland Clinic (Cleveland, $\mathrm{OH}$ ) underwent cardiac surgical procedures requiring $\mathrm{CPB}$. Patients with missing intraoperative hematocrit (HCT) values or aged younger than 18 years were excluded. Among the remaining 15,115 patients, $7942(53 \%)$ did not receive an intraoperative or postoperative RBC transfusion. Another 7173 (47\%) received intraoperative 

Abbreviations and Acronyms
$\mathrm{CPB}=$ cardiopulmonary bypass
eGFR $=$ estimated glomerular filtration rate
$\mathrm{HCT}=$ hematocrit
$\mathrm{LOS}=$ length of stay
$\mathrm{RBC}=$ red blood cell

or postoperative transfusions, or both. Among the transfused patients, 1202 $(17 \%)$ had only intraoperative RBC transfusions and were included in the study group. We included only intraoperative RBC transfusions to avoid potential confounding associated with RBC transfusion occurring after the morbidity event.

Our final study cohort comprised 9144 patients: 7942 nontransfused $(87 \%)$ and 1202 transfused only intraoperatively (13\%). For comparison, the study cohort was divided into 4 groups (Figure E1):

1. No negative exposures: nadir $\mathrm{HCT} \geq 25 \%$ without $\mathrm{RBC}$ transfusion $(\mathrm{n}=6937 ; 76 \%)$.

2. Single negative exposure: nadir HCT $\geq 25 \%$ with $\mathrm{RBC}$ transfusion $(\mathrm{n}=246 ; 2.7 \%)$.

3. Single negative exposure: nadir HCT $<25 \%$ without RBC transfusion $(\mathrm{n}=1005 ; 11 \%)$.

4. Double negative exposure: nadir HCT $<25 \%$ with RBC transfusion $(\mathrm{n}=956 ; 10 \%)$.

Baseline and perioperative variables were retrieved from the Cleveland Clinic Cardiovascular Information Registry and the Cardiothoracic Anesthesia Database, ongoing, prospective, concurrent registries of all cardiac operations maintained concurrently with patient care. They have been approved for use in research by the Institutional Review Board, with patient consent waived.

\section{End Points}

End points were markers of end-organ dysfunction (perioperative myocardial infarction, renal and hepatic failure, neurologic complications, and duration of postoperative ventilatory support), hospital mortality, and long-term survival. Serial values of specific markers of end-organ dysfunction included estimated glomerular filtration rate (eGFR) and troponin release level. Intensive care unit and postoperative lengths of stay (LOS) were used as surrogates for resource use, as was duration of postoperative ventilatory support. Hospital morbidities were recorded prospectively, according to definitions from the Society of Thoracic Surgeons National Adult Cardiac Database (http://www.ctsnet.org/file/rptDataSpecifications 252_1_ForVendorsPGS.pdf).

Vital status was determined using Cardiovascular Information Registry follow-up data supplemented with Social Security Death Master File information. ${ }^{8,9}$ Median follow-up was 3.7 years, with $25 \%$ of patients followed up for more than 5 years and $10 \%$ for more than 6 years; 33,775 patient-years of data were available for analysis. Nadir HCT was defined as the lowest intraoperative HCT value obtained from intraoperative arterial blood samples.

\section{Data Analysis}

Categorical variables are summarized by frequency and percentage, and continuous variables by mean $\pm \mathrm{SD}$, or by 15 th, 50 th (median), and 85 th percentiles when values are skewed. Comparisons were made using the $\chi^{2}$ test for categorical data and the Wilcoxon rank-sum or Kruskal-Wallis nonparametric test (for $>2$ categories) for continuous data. Multiple imputation using the Markov chain Monte Carlo technique was used to impute missing values. Fivefold multiple imputation was performed with PROC MI (SAS version 9.1; SAS Institute, Inc, Cary, NC). The estimated regression coefficients and their variance-covariance matrix for each of the 5 imputed complete data sets were then combined following Rubin's methodology ${ }^{10}$ (PROC MIANALYZE; SAS Institute, Inc).

Adjusted effects of the 4 groups on outcomes were analyzed using propensity-score methods. ${ }^{11,12}$ By using polytomous logistic regression (generalized logit link with group 1 as the reference) and variables listed in Appendix E1, we identified variables associated with group membership. Having established a parsimonious model, we added other variables representing groups of patients who may be related to these 4 groups (saturated model). Three propensity scores (probability of being in groups 2,3, and 4) were then estimated. Similar to traditional 2-group propensityscore strategies, we used the scores in 2 ways: (1) subclassification approach, in which we stratified the study population into 64 strata based on the 3 scores, then adjusted for these strata in the outcome analyses of eGFR, troponin, ventilatory support time, and postoperative LOS; and (2) propensity-score adjustment, in which we forced the 3 scores into the multivariable model of short- and long-term survival.

We used multivariable linear regression (PROC REG; SAS Institute, Inc) and variables listed in Appendix E1 to identify variables associated with continuous outcomes (eGFR, postoperative LOS, troponin, and ventilatory support time) and multivariable binary logistic regression (PROC LOGISTIC; SAS Institute, Inc) for binary outcomes.

Short- and long-term survival were assessed nonparametrically using the Kaplan-Meier estimator and parametrically using a multiphase hazard model. ${ }^{13}$ The parametric model was used to resolve several phases of instantaneous risk of the event (hazard function) and to estimate shaping parameters. Multivariable analyses were performed in the hazard function domain. The final model was adjusted further by forcing in the 3 propensity scores.

Bootstrap aggregation (bagging) was used for variable selection. ${ }^{14}$ $P=.05$ was set for retention of variables. This was a 4-step process. First, a patient was randomly selected from the original data set to begin a new data set. The original data set continued to be sampled until the new data set was $100 \%$ the size of the original. Second, risk factors were identified using automated forward stepwise selection. Third, results of the variable selection were stored. These 3 steps were repeated 500 times. Finally, the frequency of occurrence of variables related to group membership was ascertained and indicated the reliability of each variable (aggregation step). All variables with bootstrap reliability of $50 \%$ or greater were retained in the final model. ${ }^{14}$

For the troponin release model, patients who underwent atrial fibrillation procedures or septal myectomy were excluded from the study cohort; and for the postoperative LOS model, patients who died in the hospital were excluded. For the troponin release, ventilatory support, and postoperative LOS models, logarithmic transformation was used as the response variable. Any one of the following was used as a neurologic complication: coma (lasting at least 24 hours), permanent stroke, transient ischemic attack, or paraplegia.

All analyses were performed using SAS version 9.1 and R software. ${ }^{15}$ The statistical significance level was set at .05. All $P$ values are 2 sided.

\section{RESULTS \\ Intraoperative Nadir HCT and RBC Transfusion}

The median intraoperative nadir HCT was $29 \%$. Total intraoperative RBC units transfused ranged from 1 to 30 , with $75 \%$ of patients receiving either 1 or 2 units. As expected, transfused patients had lower intraoperative nadir HCT values than nontransfused patients (Figure 1). Baseline and perioperative variables, according to exposure group, are presented in Table 1. Compared with patients not having the negative exposures of anemia and transfusion, those exposed to both were more likely to be older, to be 


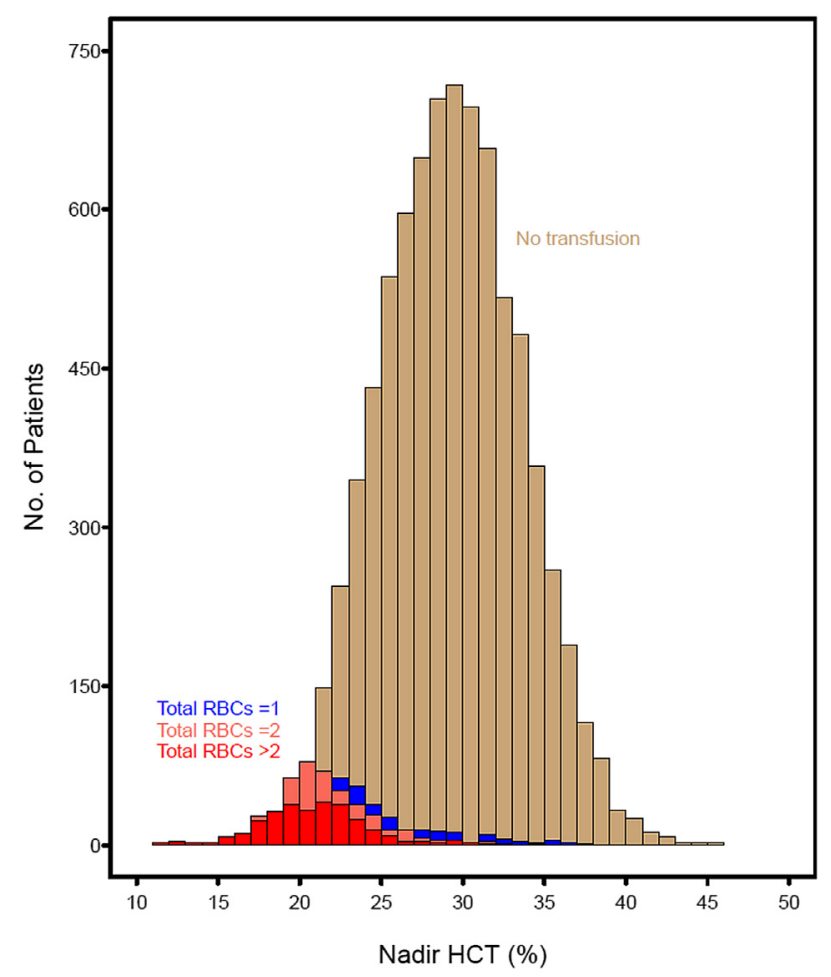

FIGURE 1. Histogram showing relationship between intraoperative nadir hematocrit $(H C T)$ and intraoperative red blood cell $(R B C)$ transfusion status.

female, and to have a lower body mass index, a lower preoperative hematocrit, and a longer CPB duration. They were also more likely to have an unstable presentation (ie, a higher prevalence of emergency operations, preoperative intra-aortic balloon pump use, and reoperations) (Table 1 and Table E1).

\section{2-Hour Minimum eGFR and Exposure Groups}

Unadjusted analysis showed differences in postoperative 72-hour minimum eGFR among the 4 groups, with more negative exposures associated with decreased renal function (Table 2 and Figure 2, A). Compared with patients not having negative exposures to anemia or transfusion, patients exposed to anemia (HCT $<25 \%$ ) alone had a lower eGFR $\left(71 \pm 27\right.$ vs $\left.78 \pm 22 \mathrm{~mL} \cdot \mathrm{min}^{-1} \cdot 1.73 \mathrm{~m}^{-2}\right)$. The next worst eGFR was noted in patients with a single exposure to transfusion without anemia $\left(68 \pm 29 \mathrm{~mL} \cdot \mathrm{min}^{-1}\right.$. $1.73 \mathrm{~m}^{-2}$ ). The greatest risk for renal dysfunction was observed in patients with a double exposure to anemia $(\mathrm{HCT}<25 \%)$ and transfusion $\left(60 \pm 26 \mathrm{~mL} \cdot \mathrm{min}^{-1}\right.$. $1.73 \mathrm{~m}^{-2}$ ), demonstrating that treating anemia with $\mathrm{RBC}$ transfusion worsened, rather than helped, renal function.

Risk-adjusted analysis of renal function shows that patients exposed to anemia (HCT $<25 \%$ ) had greater renal dysfunction than those who were not anemic (Table 3, Figure 3, A, and Table E2). However, patients with anemia (HCT $<25 \%$ ) who also received an intraoperative transfusion fared worse than those who were anemic but not transfused.

\section{4-Hour Mean Troponin Release and Exposure Groups}

Unadjusted analysis revealed that patients with both anemia (HCT $<25 \%$ ) and intraoperative RBC transfusion had greater troponin release than those with anemia (HCT $<25 \%$ ) alone, suggesting increased myocardial injury (Table 2 and Figure 2, B).

Risk-adjusted analysis showed that patients with exposure to anemia (HCT $<25 \%$ ) alone did not have a significant increase in troponin release unless they also were transfused (Table 3, Figure 3, B, and Table E3). Furthermore, patients without anemia (HCT $\geq 25 \%$ ) who received an intraoperative transfusion to avoid it did not have a significantly greater increase in troponin release than those with no negative exposures.

\section{Ventilatory Support Duration and Exposure Groups}

Unadjusted analysis showed that patients exposed to intraoperative RBC transfusion with (HCT $<25 \%$ ) or without anemia had the longest postoperative ventilatory support duration (Table 2 and Figure 2,C). However, in the risk-adjusted analysis, patients with any negative exposure to anemia (HCT $<25 \%$ ) and RBC transfusion had longer ventilation times than patients without negative exposures (Table 3, Figure 3, $C$, and Table E4).

\section{Postoperative Length of Stay and Exposure Groups}

Unadjusted analysis showed that patients who received intraoperative RBC transfusion with (HCT $<25 \%$ ) or without anemia had the longest postoperative LOS, suggesting increased resource use (Table 2 and Figure 2,D). This association persisted in the risk-adjusted analysis (Table 3, Figure 3, D, and Table E5).

\section{Other Complications and Exposure Groups}

Unadjusted analysis revealed that neurologic complications occurred in $2.3 \%$ of patients with exposure to both anemia (HCT $<25 \%$ ) and intraoperative RBC transfusion, compared with $1 \%$ for those without anemia (HCT $\geq 25 \%)$ and no transfusion $(P=.004$; Table 2$)$. However, there was no statistically significant difference in occurrences among the exposure groups after riskadjusted analysis $(P>.2)$. The prevalence of hepatic dysfunction was similar among the groups (Table 2), and this held after risk adjustment.

\section{Short- and Long-Term Survival and Exposure Groups}

The hazard function for death after surgery demonstrated an early decreasing and a late increasing hazard phase. Unadjusted analysis showed differences between groups 
TABLE 1. Patient and procedural variables stratified by intraoperative nadir HCT and intraoperative RBC transfusion

\begin{tabular}{|c|c|c|c|c|c|c|c|c|c|}
\hline \multirow[b]{3}{*}{ Variable } & \multicolumn{8}{|c|}{ Intraoperative nadir HCT and intraoperative RBC transfusion groups } & \multirow{3}{*}{$\begin{array}{c}P \\
\text { value }\end{array}$} \\
\hline & \multicolumn{2}{|c|}{$\begin{array}{c}\text { Nadir HCT } \geq 25 \\
\text { and } R B C=0 \\
(\text { total } N=6937)\end{array}$} & \multicolumn{2}{|c|}{$\begin{array}{c}\text { Nadir HCT }<25 \\
\text { and } \mathbf{R B C}=\mathbf{0} \\
(\text { total } \mathrm{N}=\mathbf{1 0 0 5}) \\
\end{array}$} & \multicolumn{2}{|c|}{$\begin{array}{c}\text { Nadir HCT } \geq 25 \\
\text { and } \mathrm{RBC}>\mathbf{0} \\
\text { (total } \mathbf{N}=\mathbf{2 4 6} \text { ) } \\
\end{array}$} & \multicolumn{2}{|c|}{$\begin{array}{c}\text { Nadir } \mathrm{HCT}<25 \\
\text { and } \mathbf{R B C}>\mathbf{0} \\
\text { (total } \mathbf{N}=\mathbf{9 5 6} \text { ) }\end{array}$} & \\
\hline & No.* & Measure $\dagger$ & No.* & Measure $\dagger$ & No.* & Measure $\dagger$ & No.* & Measure $\dagger$ & \\
\hline \multicolumn{10}{|l|}{ Demographics } \\
\hline Age, y & 6937 & $59 \pm 13$ & 1005 & $63 \pm 14$ & 246 & $64 \pm 14$ & 956 & $69 \pm 13$ & $<.001$ \\
\hline Female sex & 6937 & $1345(19)$ & 1005 & $658(65)$ & 246 & $80(33)$ & 956 & $643(67)$ & $<.001$ \\
\hline \multicolumn{10}{|l|}{ Race } \\
\hline White & 6881 & $6343(92)$ & 998 & $864(87)$ & 244 & $226(93)$ & 940 & $814(87)$ & $<.001$ \\
\hline Other & 6881 & $538(7.8)$ & 998 & $134(13)$ & 244 & $18(7.4)$ & 940 & $126(13)$ & $<.001$ \\
\hline Preoperative BMI, $\mathrm{kg} \cdot \mathrm{m}^{-2}$ & 6813 & $29 \pm 5.7$ & 995 & $28 \pm 6.4$ & 242 & $29 \pm 5.7$ & 934 & $28 \pm 6.3$ & $<.001$ \\
\hline \multicolumn{10}{|l|}{ Cardiac comorbidity } \\
\hline NYHA functional class & 5979 & & 882 & & 207 & & 829 & & $<.001$ \\
\hline I & & $1854(31)$ & & $206(23)$ & & $53(26)$ & & $161(19)$ & \\
\hline II & & 2944 (49) & & $411(47)$ & & $79(38)$ & & $373(45)$ & \\
\hline III & & $1093(18)$ & & $242(27)$ & & $65(31)$ & & $248(30)$ & \\
\hline IV & & $88(1.5)$ & & $23(2.6)$ & & $10(4.8)$ & & $47(5.7)$ & \\
\hline Emergency operation & 6935 & $24(0.35)$ & 1005 & $2(0.20)$ & 246 & $8(3.3)$ & 956 & $28(2.9)$ & $<.001$ \\
\hline Prior myocardial infarction & 6937 & $1371(20)$ & 1005 & $207(21)$ & 246 & $90(37)$ & 956 & $296(31)$ & $<.001$ \\
\hline $\begin{array}{l}\text { Preoperative atrial fibrillation/ } \\
\text { flutter }\end{array}$ & 6720 & $654(9.7)$ & 981 & $92(9.4)$ & 240 & $40(17)$ & 925 & $96(10)$ & .005 \\
\hline Prior cardiac operation & 6937 & $898(13)$ & 1005 & $142(14)$ & 246 & $115(47)$ & 956 & $328(34)$ & $<.001$ \\
\hline Heart failure & 6937 & $1146(17)$ & 1005 & $255(25)$ & 246 & $82(33)$ & 956 & $358(37)$ & $<.001$ \\
\hline Preoperative IABP use & 6937 & $19(0.27)$ & 1005 & $7(0.70)$ & 246 & $6(2.4)$ & 956 & $7(0.73)$ & $<.001$ \\
\hline Cardiogenic shock & 6937 & $21(0.30)$ & 1005 & $5(0.50)$ & 246 & $4(1.6)$ & 956 & $7(0.73)$ & .003 \\
\hline Ejection fraction, $\%$ & 6728 & $54 \pm 11$ & 981 & $54 \pm 11$ & 234 & $49 \pm 14$ & 910 & $52 \pm 12$ & $<.001$ \\
\hline $\begin{array}{l}\text { Coronary artery disease } \\
(\geq 50 \% \text { stenosis })\end{array}$ & 6811 & $2311(34)$ & 981 & $317(32)$ & 237 & $86(36)$ & 918 & 397 (43) & $<.001$ \\
\hline \multicolumn{10}{|l|}{ Noncardiac comorbidity } \\
\hline History of endocarditis & 6937 & $226(3.3)$ & 1005 & $55(5.5)$ & 246 & $17(6.9)$ & 956 & $81(8.5)$ & $<.001$ \\
\hline History of smoking & 6933 & $3526(51)$ & 1002 & $470(47)$ & 246 & $152(62)$ & 955 & $512(54)$ & .001 \\
\hline $\begin{array}{l}\text { History of peripheral arterial } \\
\text { disease }\end{array}$ & 6937 & $1683(24)$ & 1005 & $292(29)$ & 246 & $114(46)$ & 956 & $439(46)$ & $<.001$ \\
\hline History of carotid disease & 6937 & $1556(22)$ & 1005 & $258(26)$ & 246 & $102(41)$ & 956 & $397(42)$ & $<.001$ \\
\hline History of COPD & 6937 & $659(9.5)$ & 1005 & $133(13)$ & 246 & $45(18)$ & 956 & $178(19)$ & $<.001$ \\
\hline History of hypertension & 6937 & $4370(63)$ & 1005 & $660(66)$ & 246 & $182(74)$ & 956 & $748(78)$ & $<.001$ \\
\hline Diabetes & 6888 & $1254(18)$ & 1002 & $229(23)$ & 243 & $61(25)$ & 945 & $314(33)$ & $<.001$ \\
\hline History of renal disease & 6937 & $91(1.3)$ & 1005 & $37(3.7)$ & 246 & $18(7.3)$ & 956 & $68(7.1)$ & $<.001$ \\
\hline Prior stroke & 6937 & $341(4.9)$ & 1005 & $80(8.0)$ & 246 & $33(13)$ & 956 & $135(14)$ & $<.001$ \\
\hline Preoperative eGFR (MDRD) & 6931 & $81 \pm 20$ & 1005 & $77 \pm 25$ & 246 & $76 \pm 31$ & 956 & $69 \pm 27$ & $<.001$ \\
\hline Bilirubin, $\mathrm{mg} \cdot \mathrm{dL}^{-1}$ & 6865 & $0.72 \pm 0.41$ & 994 & $0.6 \pm 0.43$ & 242 & $0.73 \pm 0.48$ & 944 & $0.62 \pm 0.54$ & $<.001$ \\
\hline Preoperative hematocrit, $\%$ & 6937 & $43 \pm 4.2$ & 1005 & $36 \pm 3.9$ & 246 & $39 \pm 6.2$ & 956 & $33 \pm 4.6$ & $<.001$ \\
\hline \multicolumn{10}{|l|}{ Procedure } \\
\hline No. of ITA grafts $(>0)$ & 6937 & $2089(30)$ & 1005 & $270(27)$ & 246 & $56(23)$ & 956 & $291(30)$ & $<.001$ \\
\hline Isolated CABG & 6937 & $1430(21)$ & 1005 & $169(17)$ & 246 & $33(13)$ & 956 & 159 (17) & .001 \\
\hline Isolated valve & 6937 & $2151(31)$ & 1005 & $330(33)$ & 246 & $46(19)$ & 956 & $216(23)$ & $<.001$ \\
\hline Valve + CABG & 6937 & $614(8.9)$ & 1005 & $115(11)$ & 246 & $27(11)$ & 956 & $165(17)$ & $<.001$ \\
\hline Other procedures & 6937 & $2742(40)$ & 1005 & $391(39)$ & 246 & $140(57)$ & 956 & $416(44)$ & $<.001$ \\
\hline No. of components & 6937 & $1.6 \pm 0.85$ & 1005 & $1.7 \pm 0.95$ & 246 & $1.8 \pm 0.96$ & 956 & $2.0 \pm 0.99$ & $<.001$ \\
\hline \multicolumn{10}{|l|}{ Times } \\
\hline Myocardial ischemia, min & 6937 & $70 \pm 28$ & 1005 & $68 \pm 30$ & 246 & $77 \pm 39$ & 956 & $80 \pm 36$ & $<.001$ \\
\hline Cardiopulmonary bypass, min & 6937 & $90 \pm 34$ & 1005 & $88 \pm 37$ & 246 & $115 \pm 45$ & 956 & $112 \pm 45$ & $<.001$ \\
\hline $1 / 1 / 2004$ to index operation, $y$ & 6937 & $3.3 \pm 1.4$ & 1005 & $3.4 \pm 1.6$ & 246 & $2.9 \pm 1.3$ & 956 & $3.4 \pm 1.5$ & $<.001$ \\
\hline
\end{tabular}

HCT, Hematocrit; RBC, red blood cell; BMI, body mass index; NYHA, New York Heart Association; IABP, intra-aortic balloon pump; COPD, chronic obstructive pulmonary disease; $e G F R$, estimated glomerular filtration rate; $M D R D$, modification of diet in renal disease; ITA, internal thoracic artery; $C A B G$, coronary artery bypass grafting. *Patients with data available. $\dagger$ Number (percentage) or mean $\pm \mathrm{SD}$. 
TABLE 2. Comparison of end-organ dysfunction and hospital complications stratified by intraoperative nadir HCT and intraoperative RBC transfusion

\begin{tabular}{|c|c|c|c|c|c|c|c|c|c|}
\hline \multirow[b]{3}{*}{ Complication } & \multicolumn{8}{|c|}{ Intraoperative nadir HCT and intraoperative RBC transfusion groups } & \multirow{3}{*}{$\begin{array}{c}P \\
\text { value }\end{array}$} \\
\hline & \multicolumn{2}{|c|}{$\begin{array}{c}\text { Nadir } H C T \geq 25 \\
\text { and } R B C=0 \\
(\text { total } N=6937)\end{array}$} & \multicolumn{2}{|c|}{$\begin{array}{c}\text { Nadir } \mathrm{HCT}<25 \\
\text { and } \mathrm{RBC}=\mathbf{0} \\
(\text { total } \mathrm{N}=\mathbf{1 0 0 5})\end{array}$} & \multicolumn{2}{|c|}{$\begin{array}{c}\text { Nadir HCT } \geq 25 \\
\text { and } R B C>0 \\
\text { (total } N=\mathbf{2 4 6})\end{array}$} & \multicolumn{2}{|c|}{$\begin{array}{c}\text { Nadir HCT }<25 \\
\text { and } \mathrm{RBC}>0 \\
(\text { total } \mathrm{N}=\mathbf{9 5 6}) \\
\end{array}$} & \\
\hline & No.* & Measure $\dagger$ & No.* & Measure $\dagger$ & No.* & Measure $\dagger$ & No.* & Measure $\dagger$ & \\
\hline 72-h Minimum eGFR (MDRD) & 6934 & $78 \pm 22$ & 1004 & $71 \pm 27$ & 245 & $68 \pm 29$ & 946 & $60 \pm 26$ & $<.001$ \\
\hline 24-h Mean troponin & 6530 & $0.23 / 0.52 / 1.5$ & 912 & $0.21 / 0.53 / 1.6$ & 228 & $0.28 / 0.67 / 1.9$ & 905 & $0.31 / 0.74 / 1.8$ & $<.001$ \\
\hline Ventilatory support, $\mathrm{h}$ & 6496 & $3.5 / 6.0 / 16$ & 971 & $3.6 / 6.4 / 17$ & 244 & $4.8 / 12 / 36$ & 948 & $4.8 / 11 / 22$ & $<.001$ \\
\hline Neurologic complication & 6937 & $72(1.0)$ & 1005 & $8(0.80)$ & 246 & $4(1.6)$ & 956 & $22(2.3)$ & .004 \\
\hline GI, MSOF, or bleeding/embolic & 6937 & $93(1.3)$ & 1005 & $15(1.5)$ & 246 & $7(2.8)$ & 956 & $18(1.9)$ & .16 \\
\hline \multicolumn{10}{|l|}{ Length of stay } \\
\hline $\mathrm{ICU}, \mathrm{h}$ & 6937 & $22 / 26 / 52$ & 1005 & $21 / 27 / 67$ & 246 & $24 / 46 / 98$ & 956 & $23 / 44 / 99$ & $<.001$ \\
\hline Postoperative, $\mathrm{d}$ & 6937 & $4.2 / 6.0 / 9.0$ & 1005 & $4.8 / 6.2 / 10$ & 246 & $5.3 / 7.9 / 13$ & 956 & $5.4 / 8.0 / 13$ & $<.001$ \\
\hline
\end{tabular}

HCT, Hematocrit; RBC, red blood cell; $e G F R$, estimated glomerular filtration rate; $M D R D$, modification of diet in renal disease; GI, gastrointestinal; $M S O F$, multisystem organ failure; $I C U$, intensive care unit. *Patients with data available. $†$ Number (percentage), mean $\pm \mathrm{SD}$, or $15 \mathrm{th} / 50 \mathrm{th} / 85$ th percentiles.

for both phases, with exposure to anemia (HCT $<25 \%$ ) and intraoperative RBC transfusion associated with the lowest survival (Figure 4). Patients with HCT $\geq 25 \%$ who were
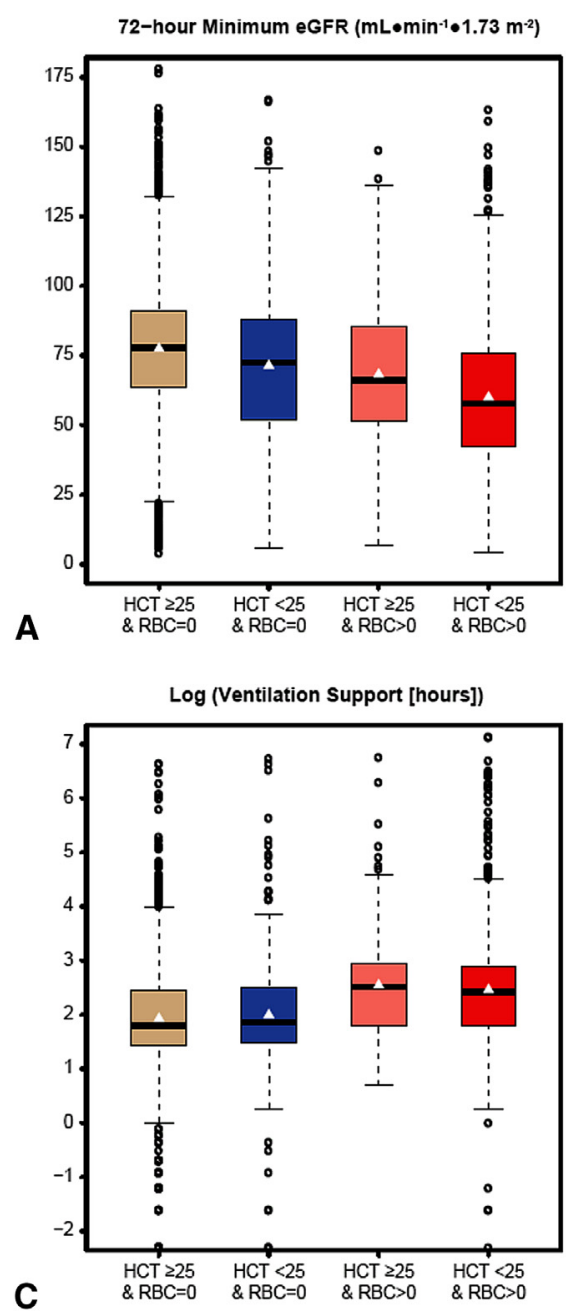

not transfused had an overall 6-year survival of $92 \%$. Survival was $82 \%$ in patients with HCT $<25 \%$ who did not receive a transfusion, and patients with $\mathrm{HCT} \geq 25 \%$
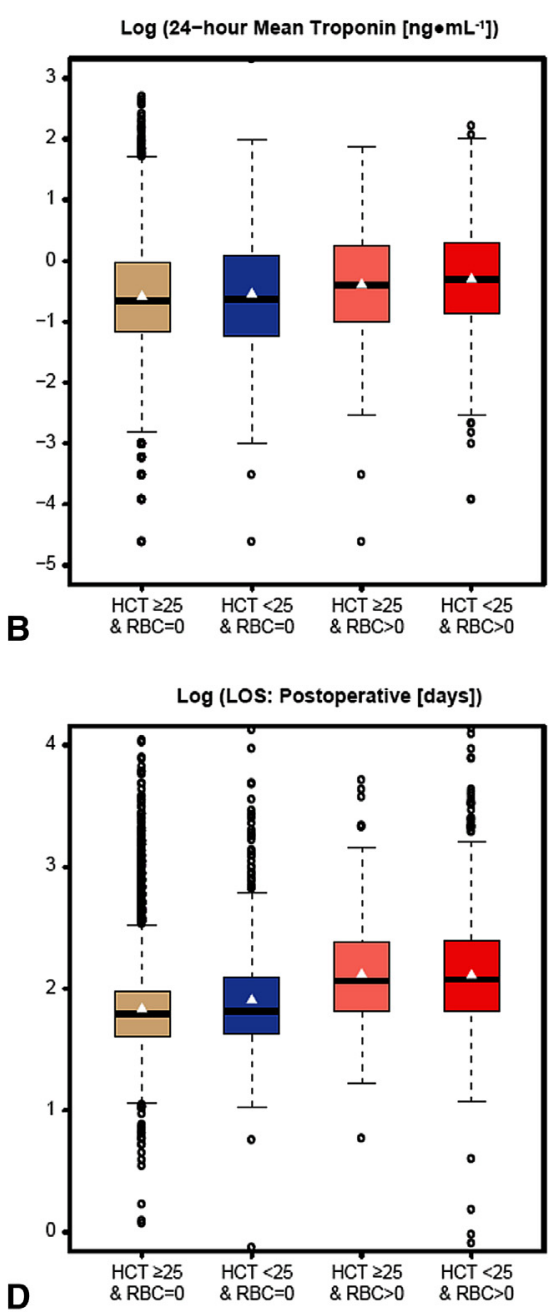

FIGURE 2. A-D, Relationship among anemia and transfusion exposure groups and outcomes. $e G F R$, Estimated glomerular filtration rate; HCT, hematocrit; $R B C$, red blood cell; $L O S$, length of stay. 
TABLE 3. Risk-adjusted effect stratified by intraoperative nadir HCT and intraoperative RBC transfusion

\begin{tabular}{|c|c|c|c|c|c|c|}
\hline \multirow[b]{2}{*}{ Outcome } & \multicolumn{2}{|c|}{ Nadir HCT $<\mathbf{2 5}$ and $\mathbf{R B C}=\mathbf{0}$} & \multicolumn{2}{|c|}{ Nadir HCT $\geq 25$ and $R B C>0$} & \multicolumn{2}{|c|}{ Nadir $\mathbf{H C T}<\mathbf{2 5}$ and $\mathbf{R B C}>\mathbf{0}$} \\
\hline & Coefficient $\pm \mathrm{SE}$ & $P$ value & Coefficient \pm SE & $P$ value & Coefficient $\pm \mathrm{SE}$ & $P$ value \\
\hline eGFR & $-1.8 \pm 0.61$ & .004 & $-1.4 \pm 1.00$ & .15 & $-2.9 \pm 0.73$ & $<.001$ \\
\hline Troponin & $0.033 \pm 0.034$ & .3 & $-0.023 \pm 0.054$ & .7 & $0.087 \pm 0.039$ & .02 \\
\hline Ventilatory support & $0.074 \pm 0.033$ & .02 & $0.304 \pm 0.052$ & $<.001$ & $0.305 \pm 0.037$ & $<.001$ \\
\hline Postoperative length of stay & $-0.0029 \pm 0.015$ & .8 & $0.11 \pm 0.025$ & $<.001$ & $0.12 \pm 0.017$ & $<.001$ \\
\hline \multicolumn{7}{|l|}{ Risk of death } \\
\hline Early & $0.49 \pm 0.36$ & .17 & $0.76 \pm 0.45$ & .09 & $0.98 \pm 0.36$ & .007 \\
\hline Late & $0.026 \pm 0.21$ & .9 & $0.18 \pm 0.25$ & .4 & $0.057 \pm 0.24$ & .8 \\
\hline
\end{tabular}

$H C T$, Hematocrit; $R B C$, red blood cell; $e G F R$, estimated glomerular filtration rate; $S E$, standard error.

who were transfused had a 74\% 6-year survival. The lowest survival $(67 \%)$ was observed in patients exposed to both anemia (HCT $<25 \%$ ) and RBC transfusion.

Risk-adjusted analysis showed that exposure to both anemia (HCT $<25 \%)$ and RBC transfusion was a risk factor for early death (Table 3 ). However, early and late survival was similar for the other exposure groups (Table 3 and Table E6).

\section{DISCUSSION}

\section{Principal Findings}

Our prior work demonstrated increased morbidity risk for both intraoperative RBC transfusion and anemia; what has

72-hour Minimum eGFR

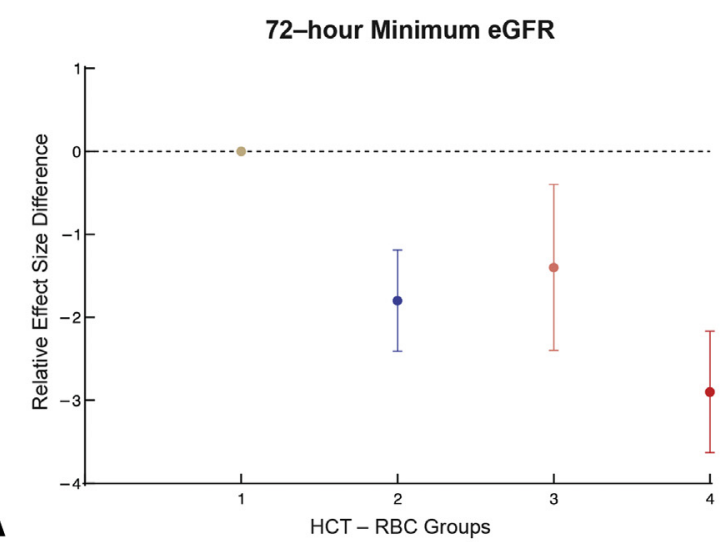

A

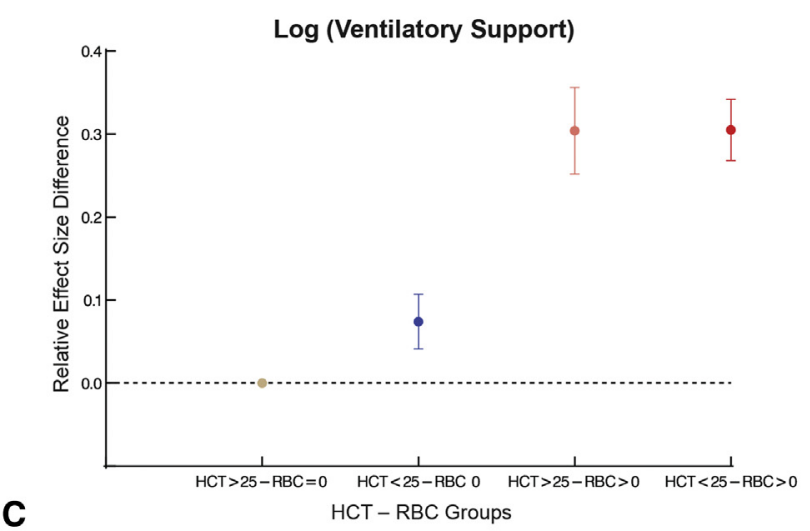

been unclear is which one, or combination, is weighted most heavily in its contribution to poorer outcomes. Although optimizing preoperative HCT before surgical intervention is the ideal, it is not uncommon for patients to be anemic when they present for surgery. Preoperative anemia is often coupled with procedural blood loss, phlebotomy, and hemodilution from intravenous fluids and CPB priming volume, all of which heighten the risk for developing or worsening anemia.

Our findings illustrate that it is preferable to allow patients to have a single negative exposure to avoid a double negative exposure (HCT $<25 \%$ and $\mathrm{RBC}$ transfusion),

\section{B}
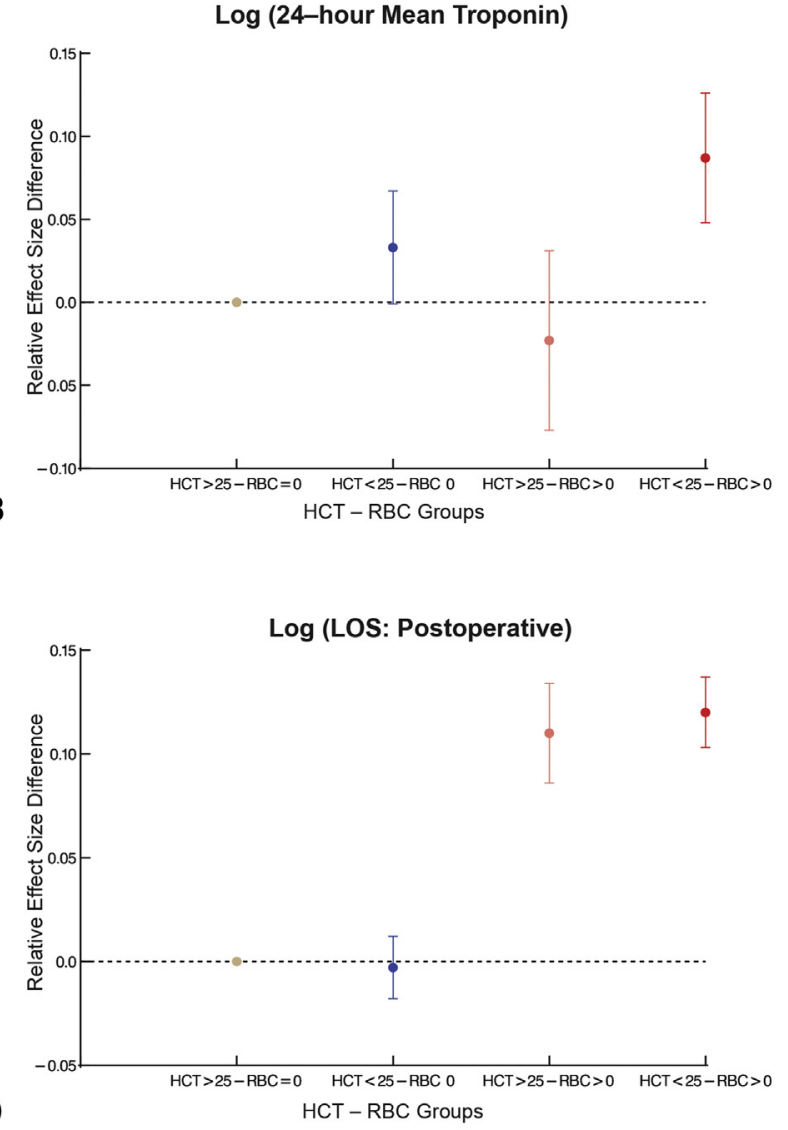

FIGURE 3. A-D, Relative effect size stratified by intraoperative red blood cell $(R B C)$ transfusion and intraoperative nadir hematocrit $(H C T)$. $e G F R$, Estimated glomerular filtration rate; LOS, length of stay. 


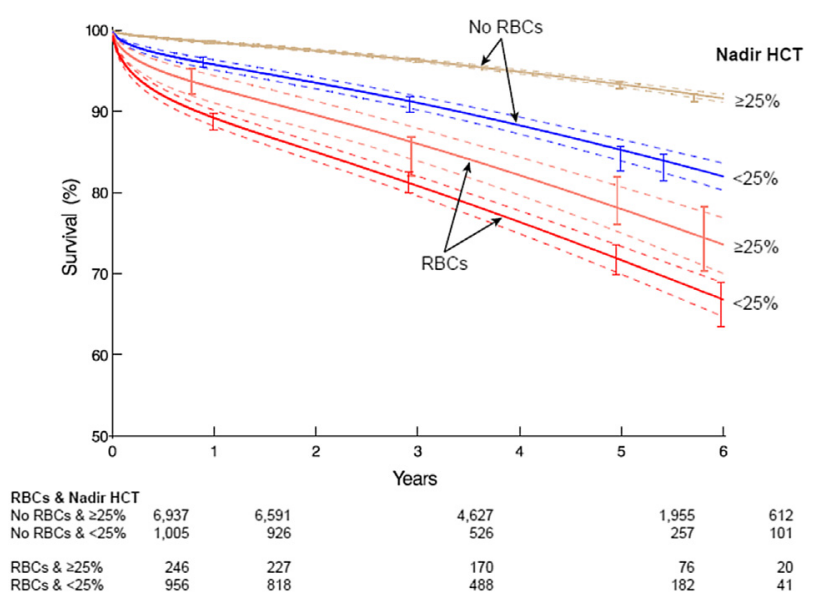

FIGURE 4. Survival after cardiac surgery stratified by intraoperative nadir hematocrit $(H C T)$ and intraoperative red blood cell $(R B C)$ transfusion exposure groups. Vertical bars, confidence limits equivalent to $\pm 1 \mathrm{SE}$; solid lines enclosed within dashed $68 \%$ confidence bands, parametric estimates. Numbers of patients remaining at risk appear below the horizontal axis.

albeit no negative exposure is preferable. Patients exposed to the combination of intraoperative anemia and transfusion had the greatest risk for renal, cardiac, and pulmonary morbidities, as well as increased resource use and earlier death. The trade-off in morbidity risk with a single exposure varied depending on the exposure.

\section{Single Exposure: Anemia}

At a certain value, nadir HCT contributes to complications as a result of a critical decrease in oxygen supply; however, the lower cutoff value is unclear. We found that patients exposed to intraoperative anemia (HCT $<25 \%$ ) alone had more renal dysfunction, more myocardial injury, and longer ventilatory support times, yet mortality was not higher. Other investigations have demonstrated increased morbidity, increased mortality, and longer postoperative LOS in cardiac surgical patients with low nadir HCT. ${ }^{3,16-19}$ Recently, our group reported more end-organ dysfunction and mortality associated with lower nadir HCT during CPB. ${ }^{2}$

Our prior investigation was unable to provide a clear cutoff value for lower nadir HCT because the effect of lower HCT and morbidity was closely tied to patient-specific risk factors and the specific morbidity measured. This investigation is consistent with our earlier work on anemia exposure in demonstrating the kidney's sensitivity to anemia and increased resource use, reflective of longer ventilation times. The Society of Thoracic Surgeons guidelines recommend tolerance of anemia down to a hemoglobin level of $6 \mathrm{~g} \cdot \mathrm{dL}^{-1}$ on CPB. Although the exact cutoff value is not widely agreed on, the general message is that anemia should be tolerated. ${ }^{20}$

\section{Single Exposure: Transfusion}

Intraoperative RBC transfusion without anemia exposure was associated with longer ventilatory support duration and postoperative LOS, with mortality trending higher than that for anemia alone. Several investigations in cardiac surgical patients have linked RBC transfusion with higher morbidity and mortality. ${ }^{5-7} \mathrm{~A}$ recent randomized trial by Hajjar and colleagues $^{21}$ found that more RBC units transfused was an independent risk factor for poor outcomes. Other studies have implicated RBC transfusion in greater cardiac and renal dysfunction, delirium, poor quality of life, impaired respiratory tract function, and more infectious complications. ${ }^{7,22,23}$

\section{Least of 3 Evils}

This investigation uniquely examined the interplay of negative exposures in a single at-risk population. Ideally, patients with preoperative anemia should have their RBC mass optimized before surgery. Use of perioperative blood conservation measures, such as antifibrinolytics, cell salvage, miniaturized bypass circuits, and retrograde autologous priming, should be implemented whenever possible. ${ }^{24-27}$ Methods are available to predict nadir HCT on $\mathrm{CPB}$, which is often the trigger for RBC transfusion $\left(\right.$ Box E1). ${ }^{28}$

When one is faced with a projection of an intraoperative nadir HCT at lower thresholds of anemia, these practice scenarios may be followed: (1) place a unit of RBCs in the CPB pump before commencing bypass to avoid patient exposure to anemia; (2) commence CPB and tolerate lower levels of HCT without RBC transfusion; or (3) commence CPB, tolerate anemia for a period of bypass time, use methods to ameliorate anemia, such as ultrafiltration, and transfuse RBCs after a period of exposure to anemia when ameliorating methods are unsuccessful. Patients who are predicted to have a nadir HCT lower than $25 \%$ despite these conservative measures, or who cannot tolerate blood conservation measures, such as retrograde autologous priming, may benefit from a unit of RBCs in the $\mathrm{CPB}$ circuit before bypass is commenced, to prevent the HCT from decreasing lower than $25 \%$ and causing 2 negative exposures.

In a recent pilot investigation, Karkouti and colleagues ${ }^{29}$ suggested treating preoperative anemia with prophylactic $\mathrm{RBC}$ transfusions as a protective measure against postoperative acute kidney injury. The authors hypothesized that transfusing patients days before surgery potentially decreased its negative effects by allowing time for functional properties of RBCs to recover and by clearing senescent RBCs. The authors did not address whether these patients had iron-deficient anemia and could have been treated with iron therapy rather than a transfusion. Certainly, in patients who are not candidates for iron or erythropoietin therapy, early transfusion might be a consideration. However, others cautioned against using $\mathrm{RBC}$ transfusion as a prophylactic strategy, noting the availability of myriad perioperative blood conservation measures that are preferable to RBC transfusion. ${ }^{30}$ 


\section{Limitations}

This is a prospective cohort investigation, and unmeasured variables have the potential to bias study results. In addition, this is a single-center investigation, which limits the generalizability of our findings. Treating HCT as a categorical, rather than a continuous, variable could influence results, depending on what cutoff is used. We chose $25 \%$ because lower than this number there were still enough patients who did and did not get transfused to allow comparative analysis. Below an HCT of $20 \%$, few patients at our institution escape RBC transfusions.

\section{CONCLUSIONS}

Ideally, all cardiac surgical patients would have preoperative HCT optimized before surgical intervention; however, the reality is that patients are prone to being exposed to both anemia and RBC transfusion perioperatively. Our findings have practical implications for clinical practice. Clearly, a double negative exposure to RBCs and anemia $(\mathrm{HCT}<25 \%$ ) carries the highest morbidity risk; however, single exposures carry increased morbidity risk as well. Managing preoperative anemia more aggressively and implementing measures to avoid development of operative anemia may circumvent negative exposures and improve patient outcomes.

We thank Tess Parry for editorial assistance.

\section{References}

1. Habib RH, Zacharias A, Schwann TA, Riordan CJ, Engoren M, Durham SJ, et al. Role of hemodilutional anemia and transfusion during cardiopulmonary bypass in renal injury after coronary revascularization: implications on operative outcome. Crit Care Med. 2005;33:1749-56.

2. Loor G, Li L, Sabik JF 3rd, Rajeswaran J, Blackstone EH, Koch CG. Nadir hematocrit during cardiopulmonary bypass: end-organ dysfunction and mortality. J Thorac Cardiovasc Surg. 2012;144:654-62.e4.

3. Ranucci M, Conti D, Castelvecchio S, Menicanti L, Frigiola A, Ballotta A, et al. Hematocrit on cardiopulmonary bypass and outcome after coronary surgery in nontransfused patients. Ann Thorac Surg. 2010;89:11-7.

4. Koch CG, Li L, Sessler DI, Figueroa P, Hoeltge GA, Mihaljevic T, et al. Duration of red-cell storage and complications after cardiac surgery. N Engl J Med. 2008; 358:1229-39.

5. Koch CG, Li L, Duncan AI, Mihaljevic T, Loop FD, Starr NJ, et al. Transfusion in coronary artery bypass grafting is associated with reduced long-term survival. Ann Thorac Surg. 2006;81:1650-7.

6. Koch CG, Li L, Duncan AI, Mihaljevic T, Cosgrove DM, Loop FD, et al. Morbidity and mortality risk associated with red blood cell and bloodcomponent transfusion in isolated coronary artery bypass grafting. Crit Care Med. 2006;34:1608-16.

7. Koch C, Li L, Figueroa P, Mihaljevic T, Svensson L, Blackstone EH. Transfusion and pulmonary morbidity after cardiac surgery. Ann Thorac Surg. 2009;88: 1410-8.

8. Boyle CA, Decoufle P. National sources of vital status information: extent of coverage and possible selectivity in reporting. Am J Epidemiol. 1990;131: $160-8$.
9. Newman TB, Brown AN. Use of commercial record linkage software and vital statistics to identify patient deaths. J Am Med Inform Assoc. 1997;4:233-7.

10. Rubin DB. Multiple Imputation for Non-Response in Surveys. New York, NY: Wiley; 1987.

11. Rosenbaum PR, Rubin DB. The central role of the propensity score in observational studies for causal effects. Biometrika. 1983;70:41-55.

12. Rubin DB. The design versus the analysis of observational studies for causal effects: parallels with the design of randomized trials. Stat Med. 2007;26: 20-36.

13. Blackstone EH, Naftel DC, Turner ME Jr. The decomposition of time-varying hazard into phases, each incorporating a separate stream of concomitant information. J Am Stat Assoc. 1986;81:615-24.

14. Breiman L. Bagging predictors. Machine Learning. 1996;24:123-40.

15. R Development Core Team. R: A Language and Environment for Statistical Computing. Vienna, Austria: R Foundation for Statistical Computing; 2010.

16. Habib RH, Zacharias A, Schwann TA, Riordan CJ, Durham SJ, Shah A. Adverse effects of low hematocrit during cardiopulmonary bypass in the adult: should current practice be changed? J Thorac Cardiovasc Surg. 2003;125:1438-50.

17. Swaminathan M, Phillips-Bute BG, Conlon PJ, Smith PK, Newman MF, Stafford-Smith M. The association of lowest hematocrit during cardiopulmonary bypass with acute renal injury after coronary artery bypass surgery. Ann Thorac Surg. 2003;76:784-91; discussion 92.

18. Karkouti K, Djaiani G, Borger MA, Beattie WS, Fedorko L, Wijeysundera D, et al. Low hematocrit during cardiopulmonary bypass is associated with increased risk of perioperative stroke in cardiac surgery. Ann Thorac Surg. 2005;80:1381-7.

19. Jonas RA, Wypij D, Roth SJ, Bellinger DC, Visconti KJ, du Plessis AJ, et al. The influence of hemodilution on outcome after hypothermic cardiopulmonary bypass: results of a randomized trial in infants. $J$ Thorac Cardiovasc Surg. 2003;126:1765-74

20. Ferraris VA, Brown JR, Despotis GJ, Hammon JW, Reece TB, Saha SP, et al. 2011 Update to the Society of Thoracic Surgeons and the Society of Cardiovascular Anesthesiologists blood conservation clinical practice guidelines. Ann Thorac Surg. 2011;91:944-82.

21. Hajjar LA, Vincent JL, Galas FR, Nakamura RE, Silva CM, Santos MH, et al. Transfusion requirements after cardiac surgery: the TRACS randomized controlled trial. JAMA. 2010;304:1559-67.

22. Surgenor SD, DeFoe GR, Fillinger MP, Likosky DS, Groom RC, Clark C, et al Intraoperative red blood cell transfusion during coronary artery bypass graft surgery increases the risk of postoperative low-output heart failure. Circulation. 2006;114:I43-8.

23. Chelemer SB, Prato BS, Cox PM Jr, O'Connor GT, Morton JR. Association of bacterial infection and red blood cell transfusion after coronary artery bypass surgery. Ann Thorac Surg. 2002;73:138-42.

24. Wang G, Bainbridge D, Martin J, Cheng D. The efficacy of an intraoperative cell saver during cardiac surgery: a meta-analysis of randomized trials. Anesth Analg. 2009; 109:320-30.

25. Raman JS, Hata M, Bellomo R, Kohchi K, Cheung HL, Buxton BF. Hemofiltration during cardiopulmonary bypass for high risk adult cardiac surgery. Int J Artif Organs. 2003;26:753-7.

26. Henry DA, Moxey AJ, Carless PA, O'Connell D, McClelland B, Henderson KM, et al. Anti-fibrinolytic use for minimising perioperative allogeneic blood transfusion. Cochrane Database Syst Rev 2001;CD001886.

27. Boodhwani M, Williams K, Babaev A, Gill G, Saleem N, Rubens FD. Ultrafiltration reduces blood transfusions following cardiac surgery: a meta-analysis. Eur J Cardiothorac Surg. 2006;30:892-7.

28. Nadler SB, Hidalgo JH, Bloch T. Prediction of blood volume in normal human adults. Surgery. 1962;51:224-32.

29. Karkouti K, Wijeysundera DN, Yau TM, McCluskey SA, Chan CT, Wong PY, et al. Advance targeted transfusion in anemic cardiac surgical patients for kidney protection: an unblinded randomized pilot clinical trial. Anesthesiology. 2012; 116:613-21.

30. Faraoni D, Ciccarella Y, Van der Linden P. Alternatives to preoperative transfusion should be preferred in anemic cardiac surgical patients instead of useless transfusion. Anesthesiology. 2012;117:919-20. author reply 21-2. 
APPENDIX E1. Variables included in multivariable analyses

Patient variables

Demographic:

Symptoms:

Ventricular function:

Coronary anatomic features:

Cardiac comorbidity:

Noncardiac comorbidity:

Experience:

Procedure variables

Support:

Procedures:
Age $(\mathrm{y}),{ }^{*}$ sex, ${ }^{*}$ race, ${ }^{*}$ height $(\mathrm{cm})$, weight $(\mathrm{kg})$, body surface area $\left(\mathrm{m}^{2}\right)$, body mass index $\left(\mathrm{kg} \cdot \mathrm{m}^{-2}\right)^{*}$

New York Heart Association functional class (I-IV), ${ }^{*}$ emergency operation*

Ejection fraction $(\%)$, * prior myocardial infarction*

Left main trunk disease, right coronary artery system disease, left circumflex coronary artery disease, left anterior descending coronary artery disease (all, any, $\geq 50 \%$ stenosis, $* \geq 70 \%$ stenosis)

Atrial fibrillation or flutter, ${ }^{*}$ hypertension, ${ }^{*}$ heart failure, ${ }^{*}$ cardiogenic shock, * intra-aortic balloon pump use,* ventricular arrhythmia, ${ }^{*}$ prior cardiac operation,* complete heart block/pacer*

History of chronic obstructive pulmonary disease, ${ }^{*}$ non-insulin-treated diabetes, ${ }^{*}$ insulin-treated diabetes, ${ }^{*}$ pharmacologically treated diabetes, ${ }^{*}$ history of peripheral artery disease, ${ }^{*}$ history of smoking, ${ }^{*}$ carotid disease, ${ }^{*}$ blood urea nitrogen $\left(\mathrm{mg} \cdot \mathrm{dL}{ }^{-1}\right),{ }^{*}$ bilirubin $\left(\mathrm{mg} \cdot \mathrm{dL}^{-1}\right),{ }^{*}$ hematocrit $(\%),{ }^{*}$ creatinine $\left(\mathrm{mg} \cdot \mathrm{dL}^{-1}\right)$, creatinine clearance $\left(\mathrm{mL} \cdot \mathrm{min}^{-1}\right)$, glomerular filtration rate $\left(\mathrm{mL} \cdot \mathrm{min}^{-1} \cdot 1.73 \mathrm{~m}^{-2}\right)$, ${ }^{*}$ prior stroke,* total cholesterol $\left(\mathrm{mg} \cdot \mathrm{dL}^{-1}\right) *$

Date of operation*

Cardiopulmonary bypass time ( $\mathrm{min}),{ }^{*}$ myocardial ischemia (min)

Isolated coronary artery bypass grafting $(\mathrm{CABG}),{ }^{*}$ isolated valve, ${ }^{*}$ isolated valve $+\mathrm{CABG}$, * internal thoracic artery graft,* other procedures, number of surgical components

*Variables included in the balancing-score model. 
BOX E1. Algorithm for calculating patient-machine hematocrit

The need for and amount of additional red blood cells to achieve a desired hemoglobin concentration early after commencing cardiopulmonary bypass is determined by the patient's blood volume $(\mathrm{VpB})$ and hemoglobin concentration before bypass (expressed as hematocrit, HCTp), and the volume of pump-oxygenator prime $(\mathrm{VmB})$ and its hemoglobin concentration (expressed as hematocrit, HCTm). Patient blood volume is estimated as follows:

$$
V p B=1000 f-w t
$$

where $f$ is the proportion of body weight attributable to blood volume; $f=0.08$ for infants and children up to 12 years of age, $f=0.065$ for older patients, and $w t$ is weight in kilograms. (These are average values for the proportion of body weight that is blood volume. More complex regression equations are available for more accurate estimates. $^{28}$ )

Patient (VpRBC) and machine (VmRBC) red blood cell $(\mathrm{RBC})$ volumes are as follows:

$$
\begin{gathered}
V p R B C=V p B \cdot H C T p \\
V m R B C=V m B \cdot H C T m
\end{gathered}
$$

Then, mixed patient-machine hematocrit (HCTpm) is as follows:

$$
H C T p m=(V p R B C+V m R B C) /(V p B+V m B) .
$$

If no blood is in the prime:

$$
H C T p m=V p R B C /(V p B+V m B) .
$$

Reprinted with permission from Kouchoukos NT, Blackstone EH, Hanley FL, Kirklin JK, eds. Kirklin/Barratt-Boyes cardiac surgery. 4th ed. Philadelphia, PA: Elsevier; 2012.

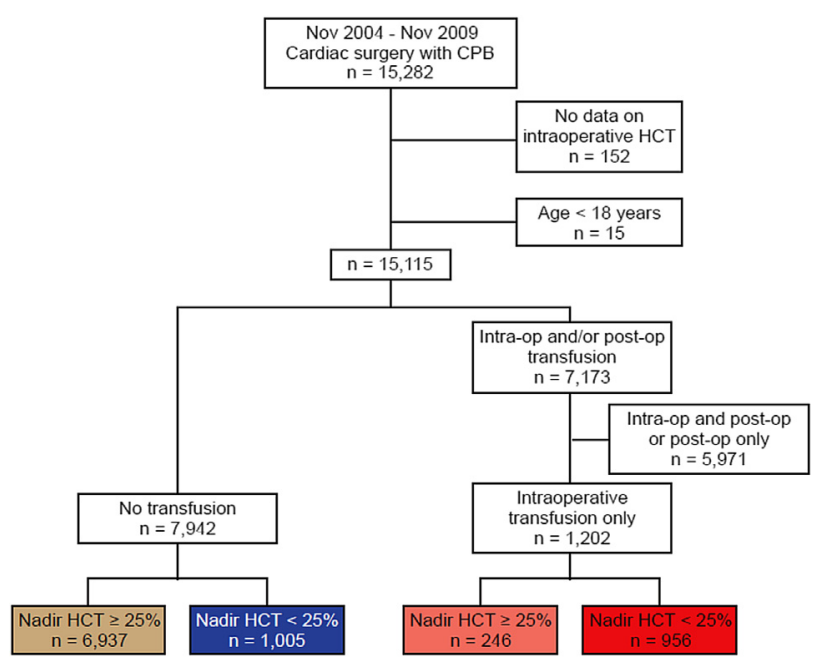

FIGURE E1. CONSORT-style diagram of patient population. The 4 groups analyzed are color coded as in manuscript Figures 1 through 4. $C P B$, Cardiopulmonary bypass; $H C T$, hematocrit; Intra-op, intraoperative; post-op, postoperative. 
TABLE E1. Patient and procedure factors associated with different exposures to anemia, transfusions, or both

\begin{tabular}{|c|c|c|}
\hline Factor & Coefficient \pm SE & $P$ value \\
\hline \multicolumn{3}{|l|}{$\begin{array}{l}\text { Nadir } \mathrm{HCT}<25 \text { and } \mathrm{RBC}=0 \text { vs nadir } \\
\qquad \mathrm{HCT} \geq 25 \text { and } \mathrm{RBC}=0\end{array}$} \\
\hline Older age & $0.019 \pm 0.0031$ & $<.001$ \\
\hline Female sex & $1.7 \pm 0.092$ & $<.001$ \\
\hline Lower body mass index & $-0.065 \pm 0.0069$ & $<.001$ \\
\hline Prior cardiac operation & $0.33 \pm 0.12$ & .007 \\
\hline No atrial fibrillation or flutter & $-0.57 \pm 0.15$ & .002 \\
\hline Lower preoperative hematocrit & $-0.36 \pm 0.011$ & $<.001$ \\
\hline $\begin{array}{l}\text { Right coronary artery disease } \\
\text { ( } \geq 50 \% \text { stenosis })\end{array}$ & $0.39 \pm 0.14$ & .004 \\
\hline Lower bilirubin* & $0.091 \pm 0.041$ & .02 \\
\hline Longer cardiopulmonary bypass time & $0.0053 \pm 0.00013$ & $<.001$ \\
\hline More recent date of operation & $0.063 \pm 0.0017$ & .03 \\
\hline \multicolumn{3}{|l|}{$\begin{array}{c}\text { Nadir HCT } \geq 25 \text { and } R B C>0 \text { vs nadir } \\
\text { HCT } \geq 25 \text { and } R B C=0\end{array}$} \\
\hline Older age & $0.025 \pm 0.0056$ & $<.001$ \\
\hline Female sex & $0.55 \pm 0.16$ & .005 \\
\hline Lower body mass index & $-0.042 \pm 0.012$ & .006 \\
\hline Prior cardiac operation & $1.6 \pm 0.12$ & $<.001$ \\
\hline Lower preoperative hematocrit & $-0.23 \pm 0.017$ & $<.001$ \\
\hline Emergency operation & $1.7 \pm 0.50$ & .009 \\
\hline $\begin{array}{l}\text { Preoperative intra-aortic balloon } \\
\text { pump use }\end{array}$ & $2.4 \pm 0.58$ & $<.001$ \\
\hline Lower bilirubin* & $0.15 \pm 0.069$ & .03 \\
\hline Prior stroke & $0.56 \pm 0.22$ & .009 \\
\hline $\begin{array}{l}\text { Procedure other than isolated CABG } \\
\text { or valve }\end{array}$ & $0.79 \pm 0.15$ & $<.001$ \\
\hline Longer cardiopulmonary bypass time & $0.015 \pm 0.0017$ & $<.001$ \\
\hline Earlier date of operation & $-0.17 \pm 0.048$ & .004 \\
\hline \multicolumn{3}{|l|}{$\begin{array}{c}\text { Nadir } \mathrm{HCT}<25 \text { and } \mathrm{RBC}>0 \text { vs nadir } \\
\text { HCT } \geq 25 \text { and } \mathrm{RBC}=0\end{array}$} \\
\hline Older age & $0.065 \pm 0.0043$ & $<.001$ \\
\hline Female sex & $2.2 \pm 0.12$ & $<.001$ \\
\hline Lower body mass index & $-0.081 \pm 0.0088$ & $<.001$ \\
\hline Prior cardiac operation & $1.4 \pm 0.13$ & $<.001$ \\
\hline No atrial fibrillation or flutter & $-1.1 \pm 0.15$ & $<.001$ \\
\hline Lower preoperative hematocrit & $-0.53 \pm 0.015$ & $<.001$ \\
\hline $\begin{array}{l}\text { Right coronary artery disease } \\
\quad(\geq 50 \% \text { stenosis })\end{array}$ & $0.400 \pm 0.16$ & .01 \\
\hline Emergency operation & $2.1 \pm 0.49$ & $<.009$ \\
\hline Lower bilirubin* & $0.21 \pm 0.047$ & $<.001$ \\
\hline Prior stroke & $0.43 \pm 0.18$ & .02 \\
\hline $\begin{array}{l}\text { Procedure other than isolated CABG } \\
\text { or valve }\end{array}$ & $0.50 \pm 0.12$ & $<.001$ \\
\hline Internal thoracic artery graft used & $0.57 \pm 0.15$ & .002 \\
\hline Longer cardiopulmonary bypass time & $0.019 \pm 0.0014$ & $<.001$ \\
\hline More recent date of operation & $0.089 \pm 0.035$ & .01 \\
\hline
\end{tabular}

$H C T$, Hematocrit; $R B C$, red blood cell; $C A B G$, coronary artery bypass grafting; $S E$, standard error. *(1/Bilirubin), inverse transformation. 
TABLE E2. Patient variables associated with lower 72-hour minimum estimated glomerular filtration rate

\begin{tabular}{|c|c|c|c|}
\hline Variable & Coefficient \pm SE & $P$ value & Reliability, \%* \\
\hline Compared with nadir $\mathrm{HCT} \geq 25$ and $\mathrm{RBC}=0$ & & & 99 \\
\hline Nadir $\mathrm{HCT}<25$ and $\mathrm{RBC}=0$ & $-1.8 \pm 0.61$ & .004 & \\
\hline Nadir HCT $\geq 25$ and $\mathrm{RBC}>0$ & $-1.4 \pm 1.00$ & .15 & \\
\hline Nadir HCT $<25$ and RBC $>0$ & $-2.9 \pm 0.73$ & $<.001$ & \\
\hline Older age & $-0.19 \pm 0.015$ & $<.001$ & 100 \\
\hline Lower preoperative eGFR & $-0.75 \pm 0.0078$ & $<.001$ & 100 \\
\hline African American & $-3.5 \pm 0.78$ & $<.001$ & 84 \\
\hline Male sex & $-1.6 \pm 0.55$ & .005 & 67 \\
\hline Cardiogenic shock & $-12 \pm 2.5$ & $<.001$ & 92 \\
\hline Diabetes (insulin dependent) & $-3.06 \pm 0.67$ & $<.001$ & 92 \\
\hline Hypertension & $-1.9 \pm 0.36$ & $<.001$ & 95 \\
\hline Heart failure & $-1.2 \pm 0.43$ & .006 & 77 \\
\hline Lower preoperative hematocrit $\dagger$ & $-14 \pm 2.6$ & $<.001$ & 99 \\
\hline Atrial fibrillation or flutter & $-1.5 \pm 0.59$ & .01 & 86 \\
\hline Higher body mass index & $-0.38 \pm 0.031$ & $<.001$ & 100 \\
\hline Longer time undergoing cardiopulmonary bypass & $-0.044 \pm 0.0052$ & $<.001$ & 100 \\
\hline History of COPD & $-1.3 \pm 0.51$ & .01 & 63 \\
\hline Lower ejection fraction $\ddagger$ & $1.5 \pm 0.44$ & .001 & 96 \\
\hline Peripheral arterial disease & $-0.92 \pm 0.40$ & .02 & 45 \\
\hline
\end{tabular}

$H C T$, Hematocrit; $R B C$, red blood cell; eGFR, estimated glomerular filtration rate; COPD, chronic obstructive pulmonary disease; $S E$, standard error. *Percentage of times variable appeared in 500 bootstrap models. $\dagger\left(40 /\right.$ Preoperative hematocrit), inverse transformation. $\ddagger(\text { Ejection fraction/50 })^{2}$, squared transformation.

TABLE E3. Variables associated with higher troponin (24-hour mean)*

\begin{tabular}{|c|c|c|c|}
\hline Variable & Coefficient $\pm \mathrm{SE}$ & $P$ value & Reliability, $\% \dagger$ \\
\hline Compared with nadir $\mathrm{HCT} \geq 25$ and $\mathrm{RBC}=0$ & & & 76 \\
\hline Nadir $\mathrm{HCT}<25$ and $\mathrm{RBC}=0$ & $0.033 \pm 0.034$ & .3 & \\
\hline Nadir HCT $\geq 25$ and $\mathrm{RBC}>0$ & $-0.023 \pm 0.054$ & .7 & \\
\hline Nadir $\mathrm{HCT}<25$ and $\mathrm{RBC}>0$ & $0.087 \pm 0.039$ & .02 & \\
\hline Atrial fibrillation or flutter & $0.13 \pm 0.053$ & .01 & 54 \\
\hline Male sex & $0.13 \pm 0.028$ & $<.001$ & 56 \\
\hline No prior cardiac operation & $-0.085 \pm 0.033$ & .01 & 97 \\
\hline Preoperative intra-aortic balloon pump use & $0.70 \pm 0.12$ & $<.001$ & 97 \\
\hline Lower preoperative eGFR $\ddagger$ & $-0.35 \pm 0.034$ & $<.001$ & 100 \\
\hline Diabetes (non-insulin dependent) & $0.075 \pm 0.036$ & .04 & 91 \\
\hline Lower weight $\S$ & $0.32 \pm 0.048$ & $<.001$ & 100 \\
\hline Longer time undergoing cardiopulmonary bypass $\|$ & $0.84 \pm 0.027$ & $<.001$ & 100 \\
\hline Higher total cholesterol & $0.012 \pm 0.0056$ & .04 & 84 \\
\hline Higher blood urea nitrogen & $0.0038 \pm 0.0014$ & .009 & 74 \\
\hline LCx disease ( $\geq 70 \%$ stenosis $)$ & $0.12 \pm 0.027$ & $<.001$ & 97 \\
\hline Nonemergency operation & $0.29 \pm 0.0104$ & .005 & 80 \\
\hline Procedure other than isolated CABG & $0.21 \pm 0.028$ & $<.001$ & 100 \\
\hline Earlier date of operation & $-0.073 \pm 0.0068$ & $<.001$ & 85 \\
\hline
\end{tabular}

$H C T$, Hematocrit; $R B C$, red blood cell; $e G F R$, estimated glomerular filtration rate; $L C x$, left circumflex coronary artery; $C A B G$, coronary artery bypass grafting; $S E$, standard error. * $\log ($ troponin - 24-hour mean); logarithmic transformation was used as the response variable. $\nmid$ Percentage of times variable appeared in 500 bootstrap models. $\ddagger \log \left(\right.$ preoperative eGFR), logarithmic transformation. $\S\left(80 /\right.$ Weight), inverse transformation. $\| \log ($ time on pump +1$)$, logarithmic transformation. $9\left(\right.$ Total cholesterol/120) ${ }^{2}$, squared transformation. 
TABLE E4. Variables associated with longer duration of postoperative ventilatory support*

\begin{tabular}{|c|c|c|c|}
\hline Variable & Coefficient \pm SE & $P$ value & Reliability, $\% \dagger$ \\
\hline Compared with nadir HCT $\geq 25$ and $\mathrm{RBC}=0$ & & & 100 \\
\hline Nadir $\mathrm{HCT}<25$ and $\mathrm{RBC}=0$ & $0.074 \pm 0.033$ & .02 & \\
\hline Nadir $\mathrm{HCT} \geq 25$ and $\mathrm{RBC}>0$ & $0.304 \pm 0.052$ & $<.001$ & \\
\hline Nadir $\mathrm{HCT}<25$ and $\mathrm{RBC}>0$ & $0.305 \pm 0.037$ & $<.001$ & \\
\hline Older age & $0.0083 \pm 0.00074$ & $<.001$ & 100 \\
\hline Higher NYHA functional class & $0.043 \pm 0.014$ & .004 & 97 \\
\hline History of smoking & $0.062 \pm 0.017$ & .004 & 85 \\
\hline Higher body mass index & $0.020 \pm 0.0015$ & $<.001$ & 100 \\
\hline History of COPD & $0.19 \pm 0.027$ & $<.001$ & 100 \\
\hline Prior cardiac operation & $0.15 \pm 0.033$ & $<.001$ & 94 \\
\hline Longer time undergoing cardiopulmonary bypass & $0.0045 \pm 0.00029$ & $<.001$ & 100 \\
\hline Preoperative intra-aortic balloon pump use & $1.2 \pm 0.12$ & $<.001$ & 100 \\
\hline Emergency operation & $0.90 \pm 0.11$ & $<.001$ & 99 \\
\hline Heart failure & $0.062 \pm 0.023$ & .008 & 84 \\
\hline Prior stroke & $0.15 \pm 0.034$ & $<.001$ & 96 \\
\hline Prior myocardial infarction & $0.12 \pm 0.022$ & $<.001$ & 83 \\
\hline Lower ejection fraction $\ddagger$ & $-0.26 \pm 0.034$ & $<.001$ & 100 \\
\hline Peripheral arterial disease & $0.089 \pm 0.022$ & $<.001$ & 68 \\
\hline Higher bilirubin $\S$ & $0.023 \pm 0.0056$ & $<.001$ & 91 \\
\hline Hypertension & $0.094 \pm 0.019$ & $<.001$ & 83 \\
\hline Procedure other than isolated CABG or valve & $0.17 \pm 0.021$ & .001 & 100 \\
\hline
\end{tabular}

$H C T$, Hematocrit; $R B C$, red blood cell; NYHA, New York Heart Association; $C O P D$, chronic obstructive pulmonary disease; $C A B G$, coronary artery bypass grafting; $S E$, standard error. * $\log ($ ventilatory support duration); logarithmic transformation was used as the response variable. †Percentage of times variable appeared in 500 bootstrap models. $\ddagger \log \left(\right.$ ejection fraction), logarithmic transformation. $\S(\text { Bilirubin })^{2}$, squared transformation.

TABLE E5. Patient and procedural variables associated with longer postoperative length of stay*

\begin{tabular}{|c|c|c|c|}
\hline Variable & Coefficient \pm SE & $P$ value & Reliability, \% $\dagger$ \\
\hline Compared with nadir $\mathrm{HCT} \geq 25$ and $\mathrm{RBC}=0$ & & & 100 \\
\hline Nadir $\mathrm{HCT}<25$ and $\mathrm{RBC}=0$ & $-0.0029 \pm 0.015$ & .8 & \\
\hline Nadir HCT $\geq 25$ and $\mathrm{RBC}>0$ & $0.11 \pm 0.024$ & $<.001$ & \\
\hline Nadir $\mathrm{HCT}<25$ and $\mathrm{RBC}>0$ & $0.12 \pm 0.017$ & $<.001$ & \\
\hline Older age $\ddagger$ & $0.058 \pm 0.0053$ & $<.001$ & 100 \\
\hline Atrial fibrillation or flutter & $0.061 \pm 0.015$ & $<.001$ & 97 \\
\hline Higher NYHA functional class & $0.040 \pm 0.0056$ & $<.001$ & 100 \\
\hline Heart failure & $0.041 \pm 0.011$ & $<.001$ & 92 \\
\hline Prior stroke & $0.10 \pm 0.016$ & $<.001$ & 100 \\
\hline History of COPD & $0.10 \pm 0.012$ & $<.001$ & 100 \\
\hline Cardiogenic shock & $0.40 \pm 0.063$ & $<.001$ & 94 \\
\hline Female sex & $0.050 \pm 0.012$ & $<.001$ & 52 \\
\hline Lower ejection fraction $\S$ & $-0.16 \pm 0.016$ & $<.001$ & 100 \\
\hline Higher blood urea nitrogen & $0.0027 \pm 0.00053$ & $<.001$ & 62 \\
\hline Higher body mass index $\|$ & $0.15 \pm 0.017$ & $<.001$ & 100 \\
\hline Diabetes (insulin dependent) & $0.053 \pm 0.017$ & .001 & 95 \\
\hline Emergency operation & $0.17 \pm 0.051$ & .006 & 58 \\
\hline Higher bilirubin & $0.059 \pm 0.0096$ & $<.001$ & 99 \\
\hline Peripheral arterial disease & $0.034 \pm 0.011$ & .007 & 62 \\
\hline Prior cardiac operation & $0.042 \pm 0.016$ & .007 & 53 \\
\hline Procedure other than isolated CABG or valve & $0.081 \pm 0.097$ & $<.001$ & 100 \\
\hline Endocarditis & $0.086 \pm 0.020$ & $<.001$ & 97 \\
\hline Longer time undergoing cardiopulmonary bypass & $0.041 \pm 0.0045$ & .004 & 99 \\
\hline Earlier date of operation & $-0.0025 \pm 0.00045$ & $<.001$ & 58 \\
\hline
\end{tabular}

$H C T$, Hematocrit; RBC, red blood cell; NYHA, New York Heart Association; COPD, chronic obstructive pulmonary disease; $C A B G$, coronary artery bypass grafting; SE, standard error. ${ }^{*} \log ($ postoperative length of stay); logarithmic transformation was used as the response variable. †Percentage of times variable appeared in 500 bootstrap models.

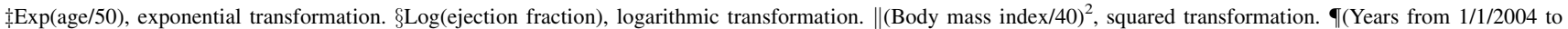
date of operation $)^{2}$, squared transformation. 
TABLE E6. Incremental risk factors for mortality

\begin{tabular}{|c|c|c|c|}
\hline Factor & Coefficient \pm SE & $P$ value & Reliability, \%* \\
\hline \multicolumn{4}{|l|}{ Early decreasing phase } \\
\hline Compared with nadir $\mathrm{HCT} \geq 25$ and $\mathrm{RBC}=0$ & & & 92 \\
\hline Nadir $\mathrm{HCT}<25$ and $\mathrm{RBC}=0$ & $0.49 \pm 0.36$ & .17 & \\
\hline Nadir $\mathrm{HCT} \geq 25$ and $\mathrm{RBC}>0$ & $0.76 \pm 0.45$ & .09 & \\
\hline Nadir $\mathrm{HCT}<25$ and $\mathrm{RBC}>0$ & $0.98 \pm 0.36$ & .007 & \\
\hline Heart failure & $0.79 \pm 0.18$ & $<.001$ & 84 \\
\hline Prior stroke & $0.66 \pm 0.21$ & .002 & 78 \\
\hline Higher bilirubin $\dagger$ & $0.052 \pm 0.013$ & .001 & 49 \\
\hline Lower preoperative eGFR $\ddagger$ & $-0.605 \pm 0.16$ & .001 & 66 \\
\hline Lower total cholesterol $\S$ & $1.1 \pm 0.46$ & .02 & 77 \\
\hline Procedure other than isolated $\mathrm{CABG}$ or valve & $0.35 \pm 0.18$ & $<.001$ & 68 \\
\hline Propensity of nadir $\mathrm{HCT}<25$ and $\mathrm{RBC}=0$ & $0.57 \pm 0.73$ & .4 & \\
\hline Propensity of nadir HCT $\geq 25$ and $\mathrm{RBC}>0$ & $2.2 \pm 1.1$ & .05 & \\
\hline Propensity of nadir HCT $<25$ and $\mathrm{RBC}>0$ & $1.4 \pm 0.44$ & .002 & \\
\hline \multicolumn{4}{|l|}{ Late increasing phase } \\
\hline Compared with nadir $\mathrm{HCT} \geq 25$ and $\mathrm{RBC}=0$ & & & 42 \\
\hline Nadir $\mathrm{HCT}<25$ and $\mathrm{RBC}=0$ & $0.026 \pm 0.21$ & .9 & \\
\hline Nadir $\mathrm{HCT} \geq 25$ and $\mathrm{RBC}>0$ & $0.18 \pm 0.25$ & .4 & \\
\hline Nadir $\mathrm{HCT}<25$ and $\mathrm{RBC}>0$ & $0.057 \pm 0.24$ & .8 & \\
\hline Older age $\|$ & $0.66 \pm 0.066$ & $<.001$ & 100 \\
\hline Emergency operation & $1.00 \pm 0.42$ & .02 & 50 \\
\hline Complete heart block/pacer & $0.41 \pm 0.17$ & .02 & 51 \\
\hline Lower ejection fraction $\Phi$ & $-0.56 \pm 0.11$ & $<.001$ & 96 \\
\hline History of COPD & $0.67 \pm 0.11$ & $<.001$ & 100 \\
\hline History of smoking & $0.43 \pm 0.11$ & $<.001$ & 98 \\
\hline Peripheral arterial disease & $0.53 \pm 0.11$ & $<.001$ & 97 \\
\hline Lower preoperative eGFR\# & $0.22 \pm 0.028$ & $<.001$ & 95 \\
\hline Lower preoperative $\mathrm{HCT}^{* *}$ & $1.5 \pm 0.51$ & .003 & 98 \\
\hline Diabetes (pharmacologically treated) & $0.49 \pm 0.102$ & $<.001$ & 50 \\
\hline Propensity of nadir $\mathrm{HCT}<25$ and $\mathrm{RBC}=0$ & $0.72 \pm 0.47$ & .12 & \\
\hline Propensity of nadir HCT $\geq 25$ and $\mathrm{RBC}>0$ & $0.503 \pm 0.76$ & .5 & \\
\hline Propensity of nadir $\mathrm{HCT}<25$ and $\mathrm{RBC}>0$ & $-0.13 \pm 0.41$ & .8 & \\
\hline
\end{tabular}

